\title{
Asymptomatic and symptomatic patients have a similar Neisseria gonorrhoeae load suggesting comparable transmission potential
}

B.M.J.W. van der Veer ${ }^{1 \star}$, C.J.P.A. Hoebe ${ }^{1,2}$, N.H.T.M. Dukers-Muijrers ${ }^{1,2}$, L.B. van Alphen1, P.F.G. Wolffs 1 Department of Medical Microbiology, Care and Public Health Research Institute (CAPHRI), Maastricht University Medical Center (MUMC+) 2 Department of Sexual Health, Infectious Diseases and Environmental Health, South Limburg Public Health Service

*e-mail: brian.vander.veer@mumc.nl

\section{Background}

Neisseria gonorrhoeae (NG) is one of the most common bacterial sexually transmitted infection. A previous model study estimated that asymptomatic carriers account for $89 \%$ of the onwards transmission ${ }^{1}$. Currently, there is limited data on transmission of NG in relation with symptoms, risk groups, and bacterial load. Therefore, we quantified NG bacterial load in a large population of men who have sex with men, heterosexual men, and women at different anatomical sites. Here we describe NG bacterial load per sample site in relation to symptoms and risk groups.

\section{Study objective}

To gain insight in associations of symptoms and risk groups with the bacterial load of NG.

\section{Methods}

- All NG positive patients with data on symptoms $(n=598)$ were included accounting for 1022 samples (218 urine, 107 vaginal, 356 anorectal, and 341 oropharyngeal) from 756 consultations between 2012 and May 2016.

- Patients were tested urogenitally at every new consultation using first-void urine (men) or a vaginal self-swab (women). On indication, an anorectal self-swab and a nurse-taken oropharyngeal swab were tested.

- NG detection by Cobas $4800 \mathrm{CT} / \mathrm{NG}$ routine testing and bacterial load was determined by interpolation of a standard curve.

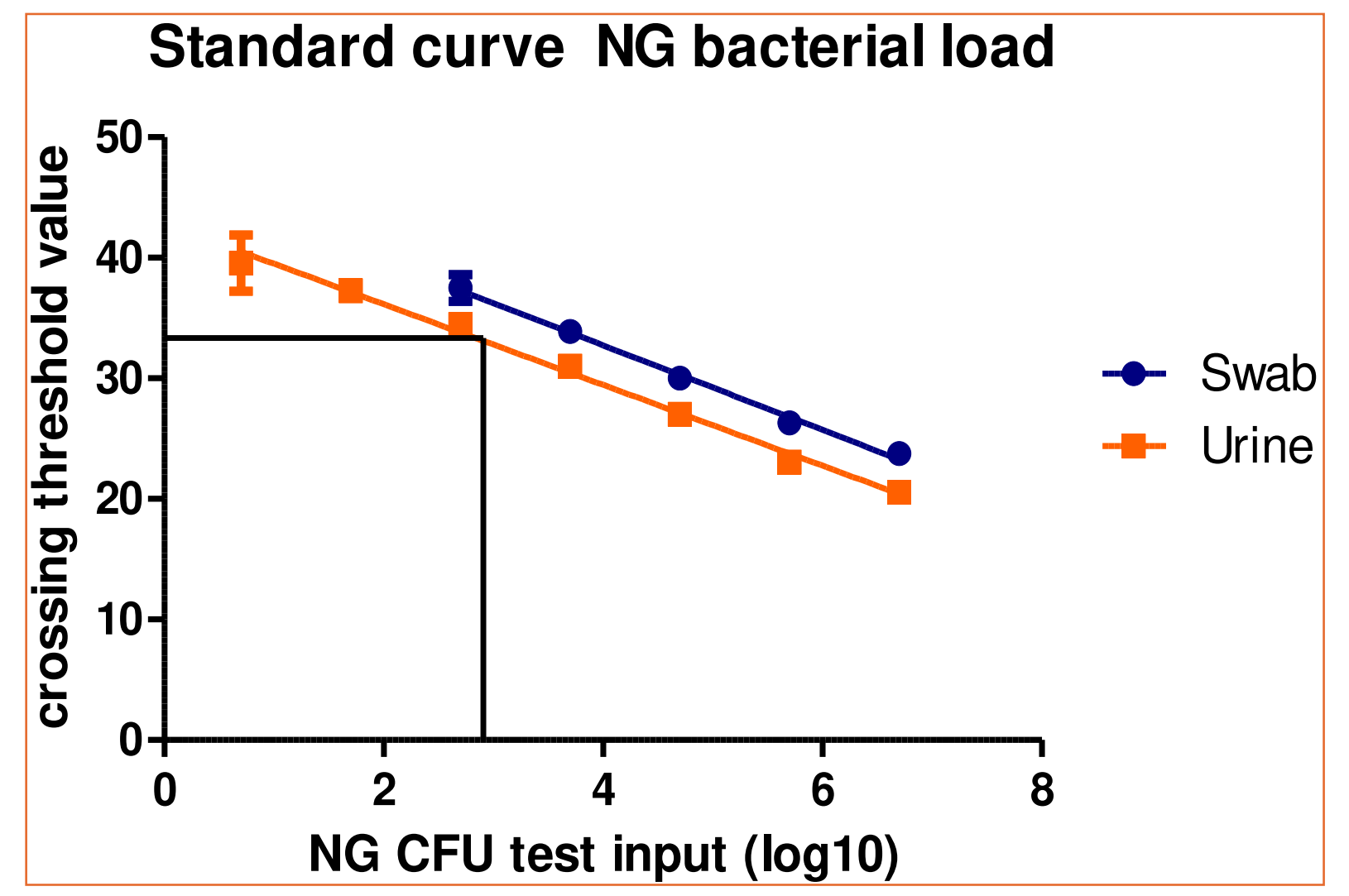

Figure 1. Load interpolation using a standard curve.

- Associations of symptoms and risk groups with NG load were assessed using linear regression models

\section{Results}

- Higher mean bacterial load in urine and anorectal samples from symptomatic patients

- Lower bacterial load in anorectal samples from women

- No significant associated variables in oropharyngeal or vaginal samples

Table 1. Associations of NG load with risk groups and symptoms per sample site.

\begin{tabular}{|c|c|c|c|c|}
\hline Sample site & Variable & $\%(n)$ & $\begin{array}{l}\text { Univariate } \\
\text { CFU/sample }(95 \% \mathrm{Cl})\end{array}$ & $\begin{array}{l}\text { Multivariable }^{\mathrm{a}} \\
\text { CFU/sample }(95 \% \mathrm{Cl})\end{array}$ \\
\hline $\begin{array}{l}\text { Urine } \\
(\mathrm{n}=218)\end{array}$ & $\begin{array}{l}\text { Risk group } \\
\text { MSM } \\
\text { Heterosexual } \\
\text { men } \\
\text { Symptoms } \\
\text { No } \\
\text { Yes }\end{array}$ & $\begin{array}{l}61.9(135) \\
38.1(83) \\
\\
59.6(130) \\
40.4(88)\end{array}$ & $\begin{array}{l}3.9 \times 10^{5}\left(2.6 \times 10^{5}-5.8 \times 10^{5}\right) \\
3.0 \times 10^{5}\left(1.6 \times 10^{5}-5.7 \times 10^{5}\right) \\
2.4 \times 10^{5}\left(1.6 \times 10^{5}-3.6 \times 10^{5}\right) \\
6.2 \times 10^{5}\left(3.3 \times 10^{5}-1.2 \times 10^{6}\right) * *\end{array}$ & $\begin{array}{l}1.8 \times 10^{5}\left(6.8 \times 10^{4}-4.5 \times 10^{5}\right) \\
4.5 \times 10^{5}\left(2.4 \times 10^{5}-8.4 \times 10^{5}\right) * *\end{array}$ \\
\hline $\begin{array}{l}\text { Vaginal } \\
(\mathrm{n}=107)\end{array}$ & $\begin{array}{l}\text { Symptoms } \\
\text { No } \\
\text { Yes }\end{array}$ & $\begin{array}{l}62.6(67) \\
37.4(40)\end{array}$ & $\begin{array}{l}8.7 \times 10^{4}\left(5.0 \times 10^{4}-1.5 \times 10^{5}\right) \\
1.6 \times 10^{5}\left(6.4 \times 10^{4}-4.0 \times 10^{5}\right)\end{array}$ & \\
\hline $\begin{array}{l}\text { Anorectal } \\
(n=356)\end{array}$ & $\begin{array}{l}\text { Risk group } \\
\text { MSM } \\
\text { Women } \\
\text { Symptoms } \\
\text { No } \\
\text { Yes }\end{array}$ & $\begin{array}{l}87.9(313) \\
12.1(43) \\
84.8(302) \\
15.2(54)\end{array}$ & $\begin{array}{l}1.9 \times 10^{5}\left(1.4 \times 10^{5}-2.6 \times 10^{5}\right) \\
6.4 \times 10^{4}\left(2.7 \times 10^{4}-1.5 \times 10^{5}\right) * \\
1.4 \times 10^{5}\left(1.0 \times 10^{5}-1.8 \times 10^{5}\right) \\
5.1 \times 10^{5}\left(2.3 \times 10^{5}-1.1 \times 10^{6}\right) * * *\end{array}$ & $\begin{array}{l}2.2 \times 10^{5}\left(9.1 \times 10^{4}-5.3 \times 10^{5}\right) \\
\underline{8.9 \times 10^{4}\left(3.7 \times 10^{4}-2.1 \times 10^{5}\right) *} \\
2.2 \times 10^{5}\left(9.1 \times 10^{4}-5.3 \times 10^{5}\right) \\
\underline{7.5 \times 10^{5}\left(3.4 \times 10^{5}-1.6 \times 10^{6}\right) * *}\end{array}$ \\
\hline $\begin{array}{l}\text { Oropharyngeal } \\
(n=341)\end{array}$ & $\begin{array}{l}\text { Risk group } \\
\text { MSM } \\
\text { Women } \\
\text { Symptoms } \\
\text { No } \\
\text { Yes }\end{array}$ & $\begin{array}{l}79.2(270) \\
20.8(71) \\
\\
95.9(327) \\
4.1(14)\end{array}$ & $\begin{array}{l}1.2 \times 10^{4}\left(9.3 \times 10^{3}-1.5 \times 10^{4}\right) \\
5.8 \times 10^{3}\left(3.3 \times 10^{3}-1.0 \times 10^{4}\right) * \\
1.0 \times 10^{4}\left(8.1 \times 10^{3}-1.3 \times 10^{4}\right) \\
1.1 \times 10^{4}\left(3.6 \times 10^{3}-3.6 \times 10^{4}\right)\end{array}$ & $\begin{array}{l}5.8 \times 10^{4}\left(3.0 \times 10^{4}-1.1 \times 10^{5}\right) \\
3.6 \times 10^{4}\left(2.1 \times 10^{4}-6.1 \times 10^{4}\right)\end{array}$ \\
\hline
\end{tabular}

\section{Conclusions}

- Urine and anorectal samples from symptomatic patients have a higher mean bacterial load but is almost within the accuracy of a PCR.

- Small differences in bacterial load from a microbiological point of view.

- Asymptomatic patients could have a similar contribution in transmission of NG if transmission solely depends on bacterial load. 